\title{
Needleless electro-spun nanofibers used for filtration of small particles
}

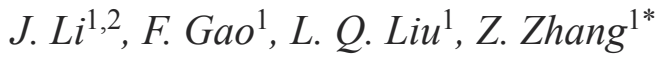 \\ ${ }^{1}$ National Center for Nanoscience and Technology, 100190 Beijing, China \\ ${ }^{2}$ University of Chinese Academy of Sciences, 100049 Beijing, China
}

Received 12 March 2013; accepted in revised form 28 April 2013

\begin{abstract}
A composite aerosol filter media was prepared by depositing nanofibers on the non-woven fabrics substrate using needleless electrospinning technique. The polyvinyl alcohol nanofibers with mean diameters of ca. $100 \mathrm{~nm}$ were used as top layers. The filtration performance was evaluated by measuring the filtration of sodium chloride nanoparticles $(75 \pm 20 \mathrm{~nm})$ through the filters. It was found that the filtration efficiency of the composite filter media for nanoparticles was increased along with the thickness of nanofibers mats which was controlled by the collection time during the electrospinning. The multi-layer arrangement for fabrication of the composite filter can achieve high filtration efficiency (up to 99.95\%) which was comparable to commercial high efficiency particulate air filters but with higher quality factor and less mass.
\end{abstract}

Keywords: nanomaterials, nanofibers, needleless electrospinning, filtration, nanoparticles

\section{Introduction}

Air pollution becomes more and more serious especially haze pollution $[1,2]$. Haze is caused by fine particles that scatter and absorb light before it reaches the observer [3]. In particular, airborne fine particulate matters especially PM 2.5 (defined as particulate matters with an aerodynamic diameter $\leq 2.5 \mu \mathrm{m}$ ) are one of the most serious sources of fine particles. PM 2.5 and its extracts can induce many human diseases [4-7]. So, there is a great need for the development of filtration technologies to prevent harmful nanoparticles affecting human healthy. One of the most valid methods of removing particles from a gas stream is via fibrous filters. According to filtration theories [8], the smaller diameter of fibers leads to better filtration efficiency.

A small diameter and large surface area of nanofibers can be achieved by the electrospinning method. The nanofiber mats have a light weight, a high permeability and a large surface area which make them appropriate for filtration and separation applications. Much work has been done in the improvement of the filtration capability of media containing electrospun nanofibers [9-14]. In spite of high filtration efficiency obtained in their works, electrospun nanofibers were obtained in low yield using needle electrospinning setup. The needle electrospinning has a very low production rate and the spinneret was frequently clogged during electrospinning $[15,16]$. Recently, needleless electrospinning appeared with the aim of producing nanofibers on a large scale [17-19]. Numerous jets are formed simultaneously from the spinneret without the influence of capillary effect, which greatly enhanced the productivity of nanofibers.

Poly(vinyl alcohol) (PVA) is a hydrophilic polymer with high biocompatibility, non-toxicity, good chemical and thermal stability [20,21]. It can be easily modified to incorporate functional groups and reacted with different crosslinking agents to form a

\footnotetext{
${ }^{*}$ Corresponding author, e-mail: zhong.zhang@nanoctr.cn

(C) BME-PT
} 
gel [22]. In this study, the needleless electrospinning equipment was set up with a stainless steel roller as spinneret. The PVA nanofibers with mean diameters of ca. $100 \mathrm{~nm}$ were deposited on nonwoven fabrics to form a composite filter material by needleless electrospinning. It showed a high efficiency and low pressure drop for the filtration of nano-sized sodium chloride $(\mathrm{NaCl})$ aerosols while depositing a thin layer of nanofibers (thickness of $2.3 \mu \mathrm{m}$ obtained by electrospinning only for $10 \mathrm{~s}$ ). The multi-layer arrangement of nanofibers mats can achieve high filtration efficiency (up to $99.95 \%$ ). That was comparable to high efficiency particulate air (HEPA) filters but with much higher quality factor and less mass.

\section{Materials and methods}

\subsection{Materials}

PVA, (typical $M_{\mathrm{w}}$ of $118000-124000,86-90 \%$ hydrolyzed) was commercial from Zhong Ke Guo
Chang Technology Co., Ltd. Beijing, China. The non-woven polypropylene (PP) fabrics with thickness of about $95 \mu \mathrm{m}$ were supplied by Handan Hengyong Protective \& Clean Products Co., Ltd. Handan, China. The commercial high efficiency particulate air (HEPA) filter media (CZU500W) were purchased from Chongqing Paper Industry Research and Design Institute Co., Ltd. China. The deionized water used in all preparations was produced by a Millipore milli-Q water purification system.

\subsection{Needleless electrospinning and the preparation of composite filter materials}

Figure 1 illustrates the overall procedure for the fabrication of the composite filter media based on needleless electrospinning. Needleless electrospinning began to attract attentions since Chaloupek et al.'s invention [17] on using a metal roller as spinneret. The setup in our laboratory is shown in Figure 1c. A stainless steel roller was put on a polyte-

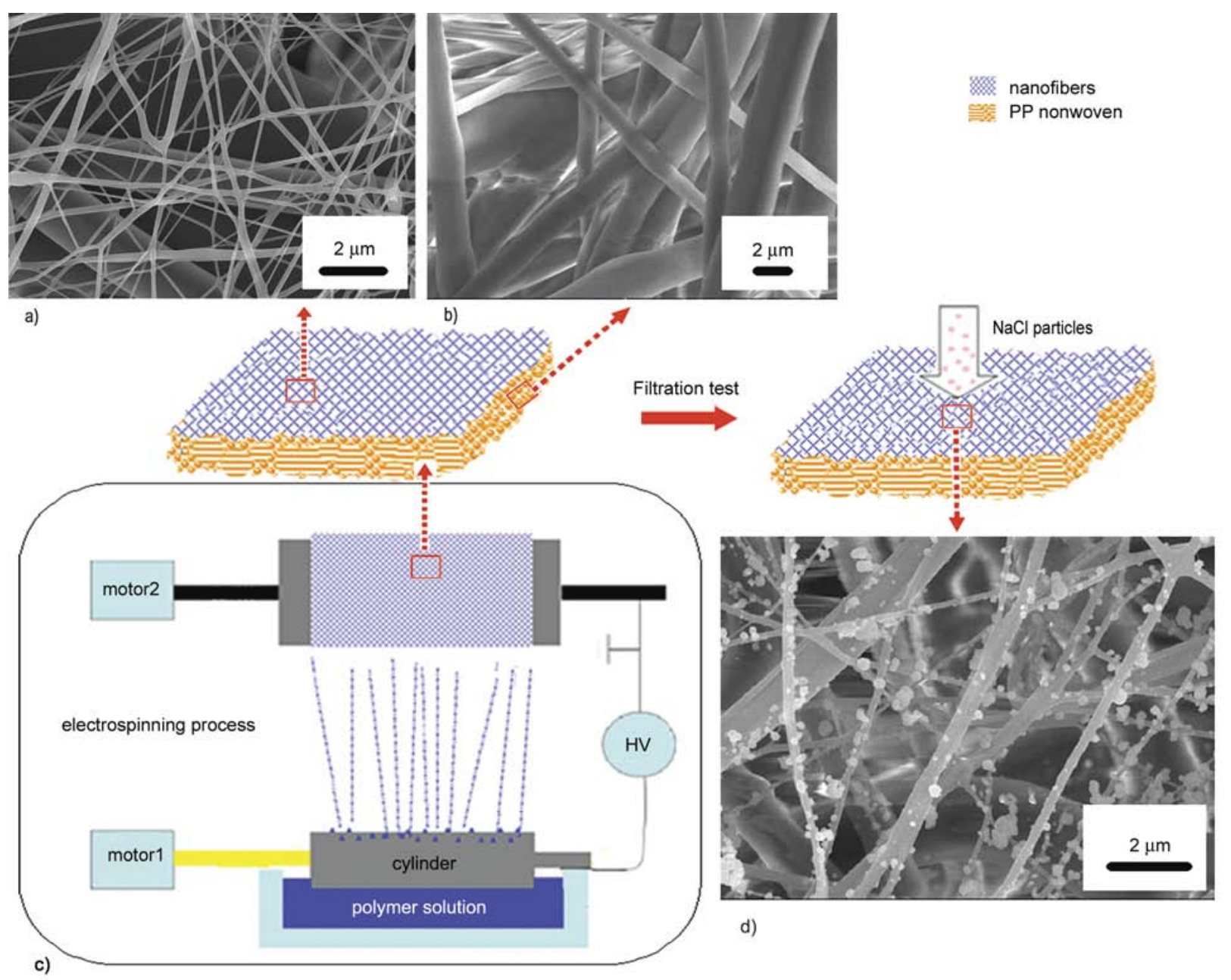

Figure 1. Schematic diagrams illustrating the fabrication of the composite filter materials. The SEM image of the composite membrane (a), PP substrate (b), the electrospinning process (c) and the SEM image of the composite membrane after filtration test $(\mathrm{d})$. 
trafluoroethylene solution tank which was used as the generator of jets. The polymer solution was loaded onto the upper surface when the rotated roller was partially immersed into polymer solution. A large number of jets can be generated from the roller surface after applying a high voltage. Another grounded roller was used for collecting electrospinning nanofibers.

Different concentrations (from 6 to $10 \mathrm{wt} \%$ ) of PVA solutions were prepared by dissolving the PVA polymer in deionized water at $60^{\circ} \mathrm{C}$, and completely dissolved by stirring. PVA nanofibers prepared by needleless electrospinning have been studied by many researchers [23]. After the polymer solutions were added to the solution tank, a voltage of $70 \mathrm{kV}$ (Spellman SL130 P300) was supplied on the positive roller for electrospinning. The distance between positive roller and collect roller was fixed at $12 \mathrm{~cm}$. The nanofibers were deposited on the nonwoven PP substrate which covered the collect roller to form the composite filter. It was dried under vacuum condition to remove the remaining solvent for the filtration test. PVA solutions can form physical gels [22] which have fine adhesive properties. After the evaporation of solvents, PVA nanofibers can well fasten on the non-woven PP fabrics without slipping away.

\subsection{Characterization}

The conductivity and viscosity of PVA solutions were measured by the conductivity meter (DDS11A, Shanghai REX Instrument Factory, China) and the HAAKE Rotational Rheometer (MARS2), respectively. The surface tension was tested by water contact angle measurement (DSA100, Germany). The morphologies of the nanofibers were observed by the scanning electron microscope (SEM, S4800, HITACHI, Japan). Prior to SEM measurement, the specimens were sputtered with gold to avoid charge accumulations. The fibers mats were weighed using the electronic balance (WA 10005, Shanghai Fangrui Istrument Co., Ltd. China). The thickness of the membrane was measured by the thickness gauge (CH-12.7-STSX, Shanghai Chuanlu Mesuring Tools Co., Ltd. China). A TSI Automated Filter Tester (Model 8130) was used to measure the filtration efficiency and pressure drop. TSI 8130 could generate neutralized monodisperse solid $\mathrm{NaCl}$ aerosols with a number median diameter of $75 \pm 20 \mathrm{~nm}$. The geometric standard deviation was smaller than 1.83. $\mathrm{The} \mathrm{NaCl}$ aerosols were flown through the filter with a continuous airflow fixed at $32 \mathrm{~L} \cdot \mathrm{min}^{-1}$. The testing time of each sample was $10 \mathrm{~s}$.

\section{Results and discussion \\ 3.1. Needleless electrospinning of PVA nanofibers}

Different concentrations (from 6 to $10 \mathrm{wt} \%$ ) of PVA solutions were prepared for sources of needleless electrospinning. The parameters such as viscosity, conductivity and surface tension were increased along with the polymeric concentration which can be seen in Figure 2 and the inserted table. The productivity of nanofibers can be achieved $10 \mathrm{~g} / \mathrm{h}$ tested from the electronic balance. Figure 3 shows the SEM images of nanofibers spun under different concentrations on PP substrate. It can be seen that the morphologies and diameters of the electrospun nanofibers obviously depended on the polymer concentrations. Discontinuous fibers and a large number of droplets were obtained when the concentration was $6 \mathrm{wt} \%$, some beads can be observed while at $7 \mathrm{wt} \%$ as shown in Figure 3a, 3b. That was caused by the little entangled polymer in lower concentration solutions which was discussed in detail in previous studies $[24,25]$. However, uniform fibers were obtained when it was higher than $7 \mathrm{wt} \%$. The diameters of fibers were increased along with the increasing of polymeric concentration which in range of ca. $91 \pm 21 \mathrm{~nm}$ for $8 \mathrm{wt} \%, 104 \pm 24 \mathrm{~nm}$ for $9 \mathrm{wt} \%$ and $117 \pm 27 \mathrm{~nm}$ for $10 \mathrm{wt} \%$ as shown in Figure $3 \mathrm{f}$. The

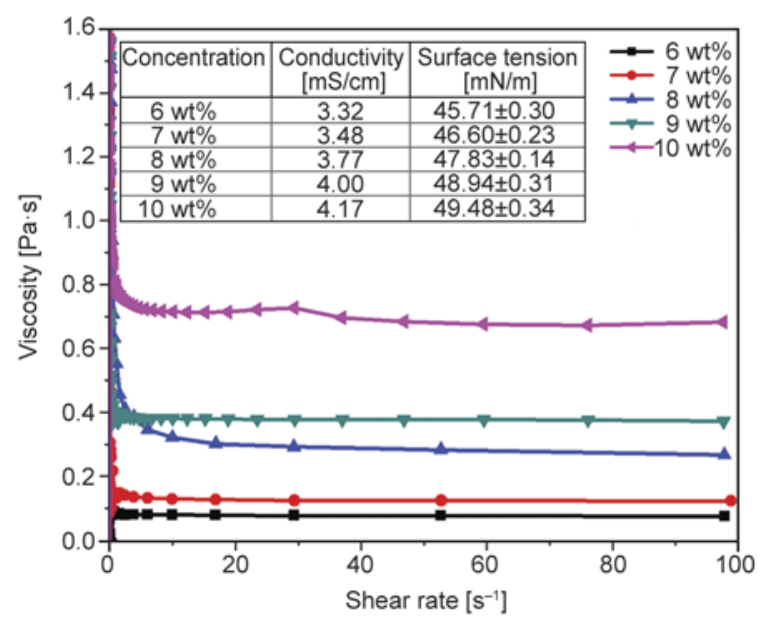

Figure 2. The viscosity versus shear rate curves of PVA solutions (the concentrations was given in figure). The inserted table shows the conductivity and surface tension of PVA solutions. 


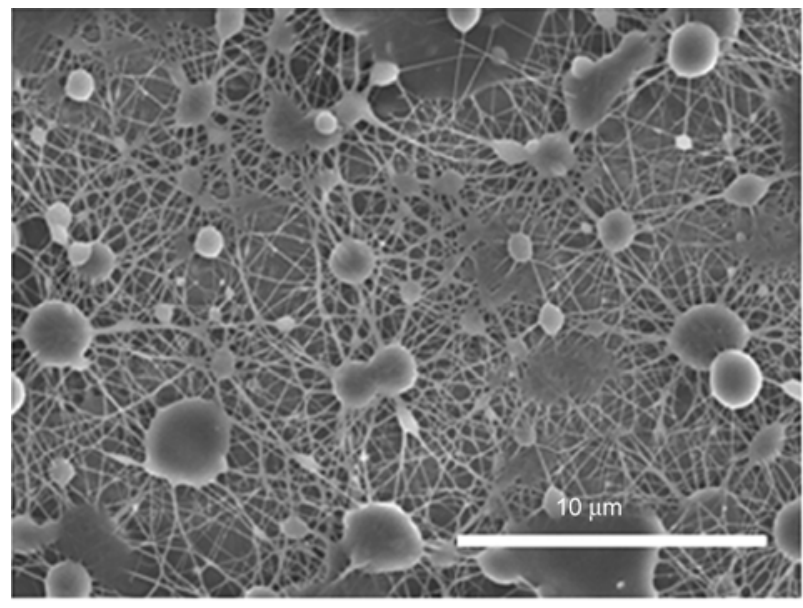

a)

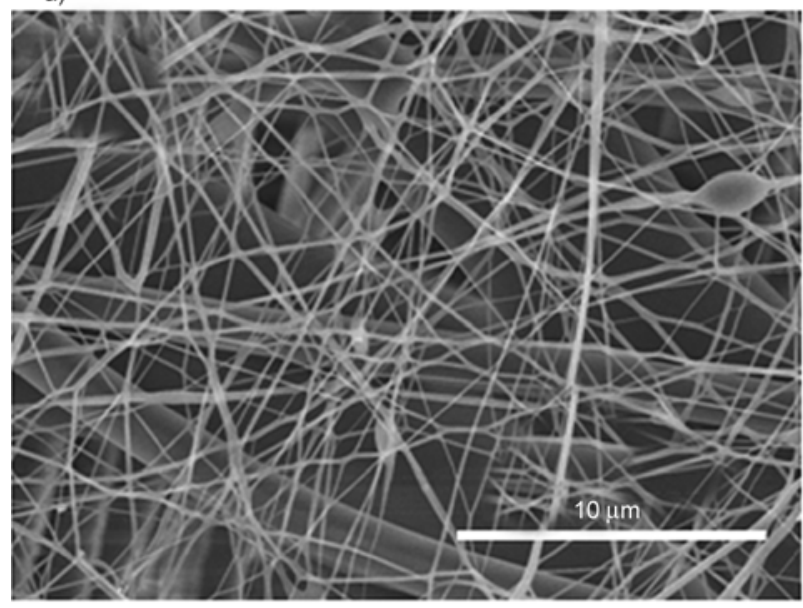

c)

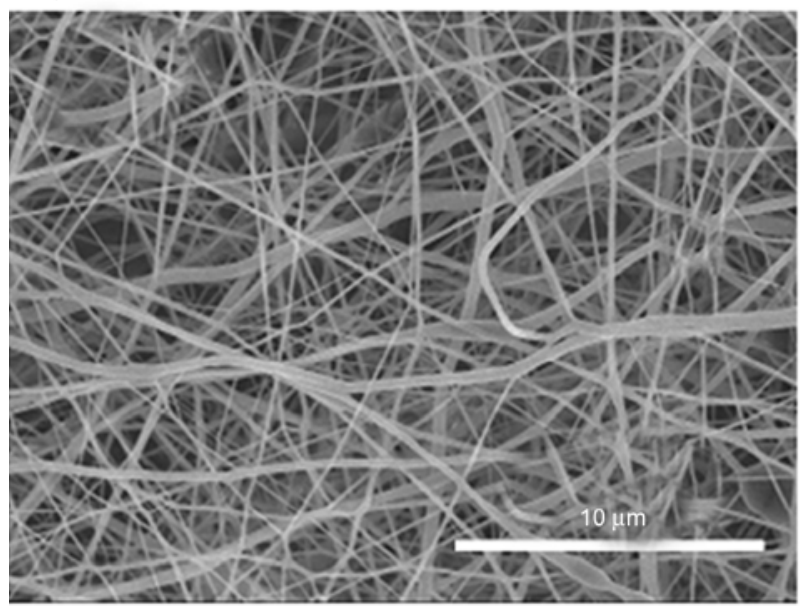

e)

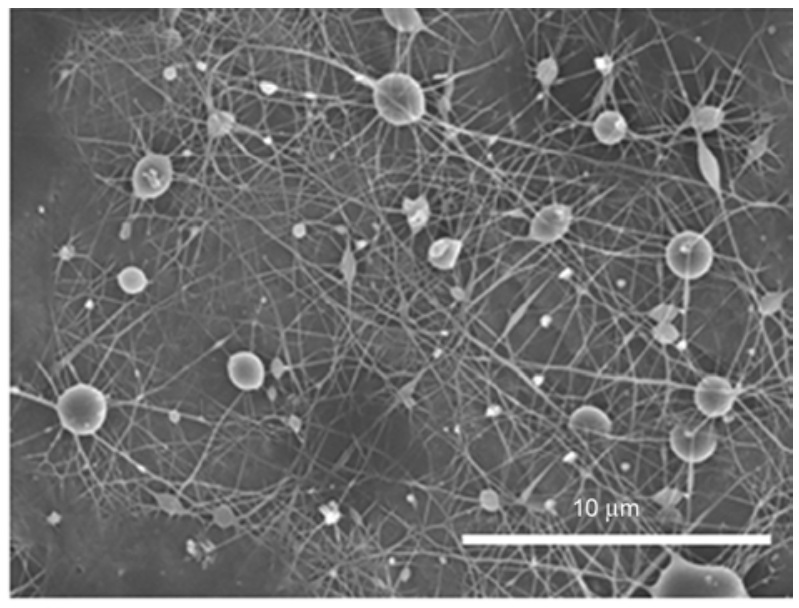

b)
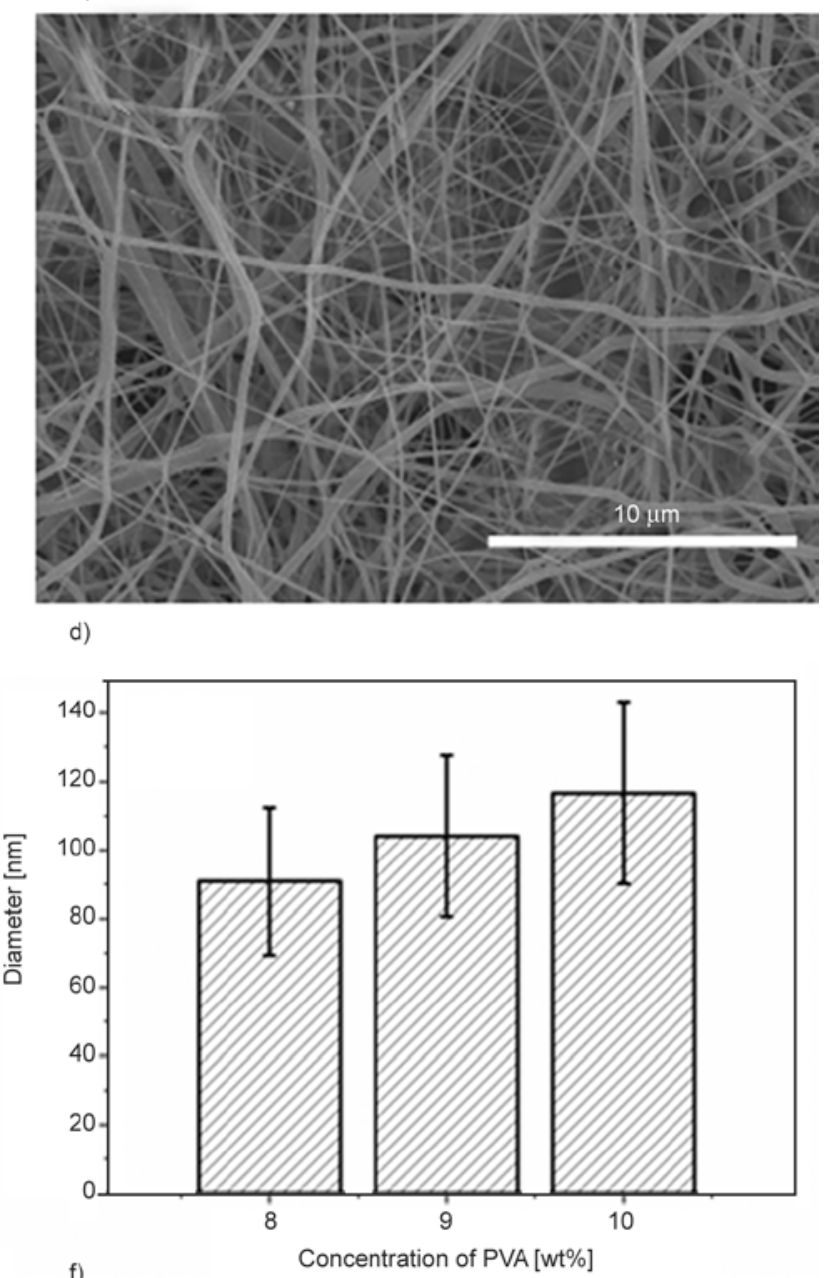

f)

Figure 3. The SEM micrographs of PVA nanofibers spun under different concentrations on PP substrate: (a) $6 \mathrm{wt} \%$; (b) $7 \mathrm{wt} \%$; (c) $8 \mathrm{wt} \%$; (d) $9 \mathrm{wt} \%$; (e) $10 \mathrm{wt} \%$. (f) The effect of PVA concentration on the diameter distribution. (The average diameter of nanofibers were measured from 100 random nanofibers on SEM micrographs using ImageJ software. Error bars indicated the standard deviation.)

thicker fibers were obtained at higher concentration. The explanation was that there were more chain entanglements and less chain mobility in higher concentration solutions. In view of the fine and uniformity of nanofibers, PVA ( $8 \mathrm{wt} \%$ ) solution was used for the following study.

\subsection{The composite filter materials for air filtration}

The nonwoven substrate with diameter of larger than $2 \mu \mathrm{m}$ was used to collect nanofibers. It is intuitive to assume that the thickness of nanofibers depended on the electrospinning time. The layers of 


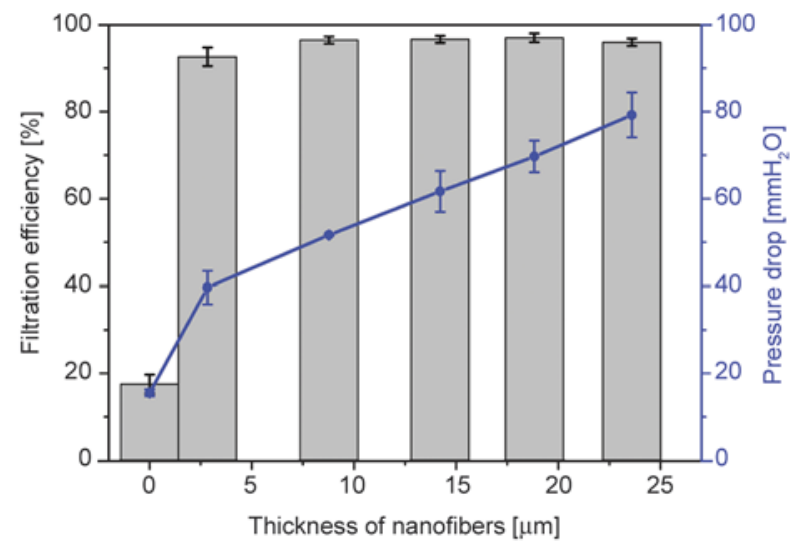

Figure 4. The filtration efficiency and drop pressure of nanofibers versus the thickness of nanofibers. (Each data point represents an average obtained from testing of five separate mats. Error bars indicate the standard deviation).

nanofibers with thickness of about 2.3, 6.3, 13.2, $18.8,24.6 \mu \mathrm{m}$ were obtained by the electrospinning time of 10,30,60, 90, $120 \mathrm{~s}$, respectively. The composite filter membranes with different thicknesses of nanofibers $(2.3,6.3,13.2,18.8,24.6 \mu \mathrm{m})$ were designated as Nn (N1, N2, N3, N4 and N5), respectively. The SEM images of composite membranes and PP substrate were shown in Figure 1a and 1b, respectively. The filtration performances are generally characterized by two basic parameters: collection efficiency and pressure drop [26]. Figure 4 shows the filtration efficiency and drop pressure of composite membranes versus the thickness of nanofibers. The PP non-woven fabrics showed lower filtration efficiency at $17.5 \%$, while it rose dramatically and reached above $92 \%$ after compositing with nanofibers. The filtration efficiencies of the composite membranes versus increased thickness of nano- fibers $(2.3,6.3,13.2,18.8,24.6 \mu \mathrm{m})$ were 92.61, 96.44, 96.63, 96.98 and 95.95\%, respectively (Figure 4). Obviously, the filtration efficiency increased along with the increasing of thickness. The filtration efficiencies can be significantly improved by compositing with a thin layer of nanofibers (only $2.3 \mu \mathrm{m}$ obtained by electrospinning for $10 \mathrm{~s}$ ).

\subsection{The filtration performances of multilayer nanofibers filter}

In order to reach higher efficiency, the above filter membranes were stacked up in different ways. The multi-layer nanofibers filter has been proposed which could realize the higher efficiency and save pressure drop in previous study [27]. The multilayer membranes $(3 * \mathrm{~N} 1,2 * \mathrm{~N} 2, \mathrm{~N} 2+\mathrm{N} 3,2 * \mathrm{~N} 3)$ and $(\mathrm{PP}+$ $\mathrm{Nn})$ were designed as shown in the left inserted image of Figure 5a. The composite filter membranes showed filtration efficiency higher than $95 \%$ after stacked with the same layer of PP, while it showed at about $35 \%$ for two layers of PP fabrics as can be seen in Figure 5a. The efficiencies of the multilayer membranes $(3 * \mathrm{~N} 1,2 * \mathrm{~N} 2, \mathrm{~N} 2+\mathrm{N} 3,2 * \mathrm{~N} 3)$ were reached at $99.95,99.60,99.63,99.78 \%$ obviously observed in Figure 5a. The filtration of nanoparticles using commercial HEPA was also tested under the same conditions. It shows the filtration efficiency of $99.95 \%$ but much higher pressure drop than the multi-layer nanofibers filters in the right inserted image of Figure 5a.

A good filtration performance requires higher efficiency but lower pressure drop. The quality factor $(Q F)$ [28] as a comprehensive parameter for measuring the filtration performance can be deduced from Equation (1):

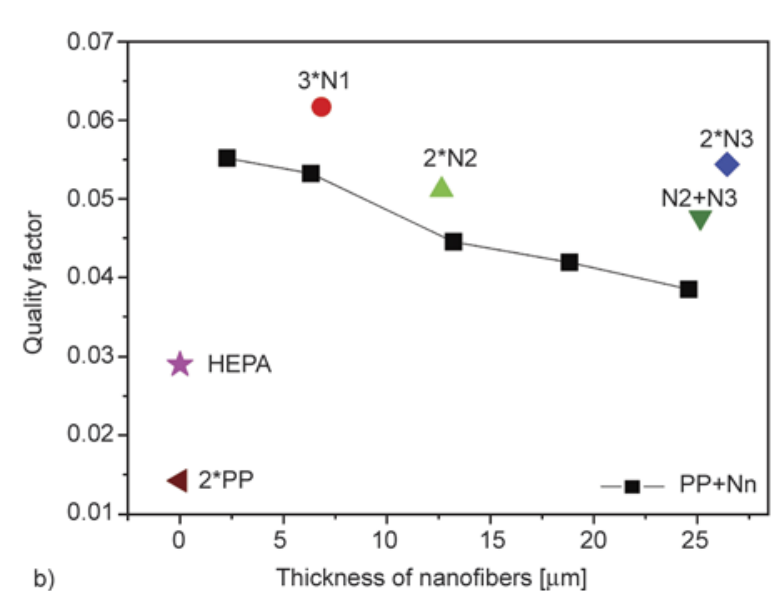

Figure 5. The filtration efficiency and drop pressure (inserted) (a) and quality factor of multi-layer composite filter media versus the thickness of nanofibers (b) 
$Q F=-\frac{\ln (1-\eta)}{\Delta P}$

where $\eta$ and $\Delta P$ are the filtration efficiency and pressure drop, respectively. The $Q F$ of the above filter media was calculated from using Equation (1) as shown in Figure $5 \mathrm{~b}$. The $Q F$ of multi-layer was much higher than HEPA. It was suggested that the filter media in our system showed better performance than HEPA for the filtration of nanoparticles. It might be used for filtration of small particles such as viruses and bacteria.

\section{Conclusions}

Uniform and continuous fibers can be obtained while the concentration was not lower than $8 \mathrm{wt} \%$ by needleless electrospinning. The PVA nanofiber mats were collected on non-woven PP fabrics to form the composite filter membranes. The filtration efficiencies can be significantly improved by compositing with a thin layer of nanofibers (only $2.3 \mu \mathrm{m}$ obtained by electrospinning for $10 \mathrm{~s}$ ). It increased with the thickness of nanofibers which were controlled by the electrospinning time. The multi-layer nanofibers showed high filtration efficiency $(99.95 \%)$ for the nanoparticles but much lower pressure drop and higher quality factor than commercial HEPA.

\section{Acknowledgements}

This project was jointly supported by a key international collaboration project (Grant No. 2011DFR50200) of the Ministry of Science and Technology of China, and the National Nature Science Foundation of China (Grant Nos. 11225210 and 51073044).

\section{References}

[1] Ji D., Wang Y., Wang L., Chen L., Hu B., Tang G., Xin J., Song T., Wen T., Sun Y., Pan Y., Liu R.: Analysis of heavy pollution episodes in selected cities of northern China. Atmospheric Environment, 50, 338-348 (2012). DOI: 10.1016/j.atmosenv.2011.11.053

[2] Ma J., Xu X., Zhao C., Yan P.: A review of atmospheric chemistry research in China: Photochemical smog, haze pollution, and gas-aerosol interactions. Advances in Atmospheric Sciences, 29, 1006-1026 (2012).

DOI: 10.1007/s00376-012-1188-7

[3] Watson J. G.: Visibility: Science and regulation. Journal of the Air and Waste Management Association, 52, 628-713 (2002). DOI: $10.1080 / 10473289.2002 .10470813$
[4] Wei A., Meng Z.: Evaluation of micronucleus induction of sand dust storm fine particles $\left(\mathrm{PM}_{2.5}\right)$ in human blood lymphocytes. Environmental Toxicology and Pharmacology, 22, 292-297 (2006).

DOI: 10.1016/j.etap.2006.04.003

[5] Nikasinovic L., Just J., Sahraoui F., Seta N., Grimfeld A., Momas I.: Nasal inflammation and personal exposure to fine particles $\mathrm{PM}_{2.5}$ in asthmatic children. Journal of Allergy and Clinical Immunology, 117, 13821388 (2006).

DOI: $10.1016 /$ j.jaci.2006.03.023

[6] Morgenstern V., Zutavern A., Cyrys J., Brockow I., Gehring U., Koletzko S., Bauer C. P., Reinhardt D., Wichmann H-E., Heinrich J.: Respiratory health and individual estimated exposure to traffic-related air pollutants in a cohort of young children. Journal of Occupational and Environmental Medicine, 64, 8-16 (2007). DOI: 10.1136/oem.2006.028241

[7] de Hartog J. J., Lanki T., Timonen K. L., Hoek G., Janssen N. A., Ibald-Mulli A., Peters A., Heinrich J., Tarkiainen T. H., van Grieken R., van Wijnen J. H., Brunekreef B., Pekkanen J.: Associations between $\mathrm{PM}_{2.5}$ and heart rate variability are modified by particle composition and beta-blocker use in patients with coronary heart disease. Environmental Health Perspectives, 117, 105-111 (2009).

DOI: 10.1289/ehp.11062

[8] Pich J.: Theory of aerosol filtration by fibrous and membrane filters. Academic Press, London (1966).

[9] Zhang S., Shim W. S., Kim J.: Design of ultra-fine nonwovens via electrospinning of Nylon 6: Spinning parameters and filtration efficiency. Materials and Design, 30, 3659-3666 (2009). DOI: $10.1016 / \mathrm{j}$. matdes.2009.02.017

[10] Yun K. M., Hogan C. J., Matsubayashi Y., Kawabe M., Iskandar F., Okuyama K.: Nanoparticle filtration by electrospun polymer fibers. Chemical Engineering Science, 62, 4751-4759 (2007). DOI: $10.1016 /$ j.ces.2007.06.007

[11] Wang N., Wang X., Ding B., Yu J., Sun G.: Tunable fabrication of three-dimensional polyamide-66 nanofiber/nets for high efficiency fine particulate filtration. Journal of Materials Chemistry, 22, 1445-1452 (2012). DOI: $10.1039 / \mathrm{c} 1 \mathrm{jm} 14299 \mathrm{~b}$

[12] Tsai P. P., Schreuder-Gibson H., Gibson P.: Different electrostatic methods for making electret filters. Journal of Electrostatics, 54, 333-341 (2002).

DOI: 10.1016/S0304-3886(01)00160-7

[13] Patanaik A., Jacobs V., Anandjiwala R. D.: Performance evaluation of electrospun nanofibrous membrane. Journal of Membrane Science, 352, 136-142 (2010). DOI: $10.1016 /$ j.memsci.2010.02.009

[14] Hoover L. A., Schiffman J. D., Elimelech M.: Nanofibers in thin-film composite membrane support layers: Enabling expanded application of forward and pressure retarded osmosis. Desalination, 308, 73-81 (2013).

DOI: 10.1016/j.desal.2012.07.019 
[15] Yu D. G., Zhou J., Chatterton N. P., Li Y., Huang J., Wang X.: Polyacrylonitrile nanofibers coated with silver nanoparticles using a modified coaxial electrospinning process. International Journal of Nanomedicine, 7, 5725-5732 (2012). DOI: $10.2147 /$ IJN.S37455

[16] Yu D. G., Li X. Y., Wang X., Chian W., Liao Y. Z., Li Y.: Zero-order drug release cellulose acetate nanofibers prepared using coaxial electrospinning. Cellulose, 20, 379-389 (2013).

DOI: $10.1007 / \mathrm{s} 10570-012-9824-\mathrm{Z}$

[17] Chaloupek J., Jirsak O., Kotek V., Lukas D., Martinova L., Sanetrnik F.: A method of nanofibres production from a polymer solution using electrostatic spinning and a device for carrying out the method. EP Patent 1673493, EU (2009).

[18] Niu H., Lin T., Wang X.: Needleless electrospinning. I. A comparison of cylinder and disk nozzles. Journal of Applied Polymer Science, 114, 3524-3530 (2009). DOI: $10.1002 / a p p .30891$

[19] Wu D., Huang X., Lai X., Sun D., Lin L.: High throughput tip-less electrospinning via a circular cylindrical electrode. Journal of Nanoscience and Nanotechnology, 10, 4221-4226 (2010).

DOI: $10.1166 / j n n .2010 .2194$

[20] Zheng H., Du Y., Yu J., Huang R., Zhang L.: Preparation and characterization of chitosan/poly(vinyl alcohol) blend fibers. Journal of Applied Polymer Science, 80, 2558-2565 (2001).

DOI: $10.1002 / a p p .1365$

[21] Kim C. K., Kim B. S., Sheikh F. A., Lee U. S., Khil M. S., Kim H. Y.: Amphiphilic poly(vinyl alcohol) hybrids and electrospun nanofibers incorporating polyhedral oligosilsesquioxane. Macromolecules, 40, 4823-4828 (2007). DOI: $10.1021 / \mathrm{Ma} 070056 \mathrm{e}$
[22] Hodge R., Edward G. H., Simon G. P.: Water absorption and states of water in semicrystalline poly(vinyl alcohol) films. Polymer, 37, 1371-1376 (1996).

DOI: 10.1016/0032-3861(96)81134-7

[23] Cengiz F., Dao T. A., Jirsak O.: Influence of solution properties on the roller electrospinning of poly(vinyl alcohol). Polymer Engineering and Science, 50, 936943 (2010).

DOI: $10.1002 /$ pen.21599

[24] McKee M. G., Wilkes G. L., Colby R. H., Long T. E.: Correlations of solution rheology with electrospun fiber formation of linear and branched polyesters. Macromolecules, 37, 1760-1767 (2004).

DOI: $10.1021 / \mathrm{ma} 035689 \mathrm{~h}$

[25] Shenoy S. L., Bates W. D., Frisch H. L., Wnek G. E.: Role of chain entanglements on fiber formation during electrospinning of polymer solutions: Good solvent, non-specific polymer-polymer interaction limit. Polymer, 46, 3372-3384 (2005).

DOI: $10.1016 /$ j.polymer.2005.03.011

[26] Matteson M. J., Orr C.: Filtration: Principles and practices. Marcel Dekker, New York (1987).

[27] Leung W. W. F., Hung C. H., Yuen P. T.: Effect of face velocity, nanofiber packing density and thickness on filtration performance of filters with nanofibers coated on a substrate. Separation and Purification Technology, 71, 30-37 (2010). DOI: $10.1016 /$ j.seppur.2009.10.017

[28] Viswanathan G., Kane D. B., Lipowicz P. J.: High efficiency fine particulate filtration using carbon nanotube coatings. Advanced Materials, 16, 2045-2049 (2004). DOI: $10.1002 / \mathrm{adma} .200400463$ 